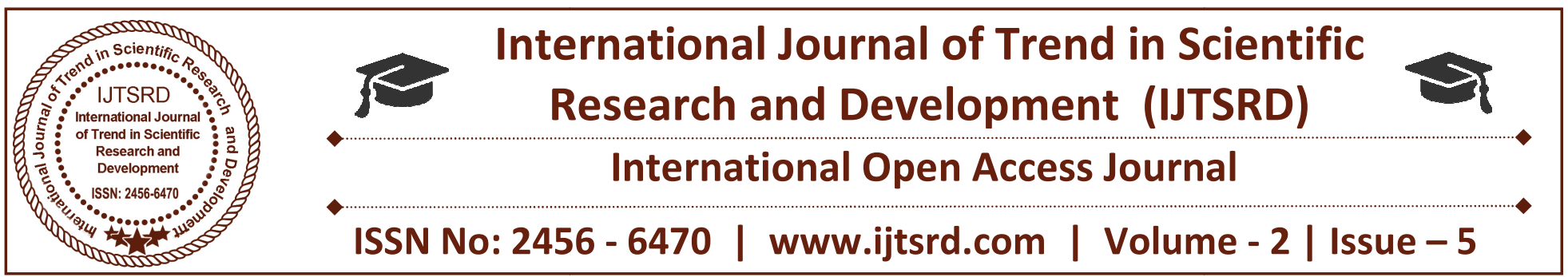

\title{
A Study of Professional Attributes Required by Culinary Students for Career Abroad
}

\author{
Rahul Bhalekar, Ms. Rinadongre \\ Assistant Professor, AISSMS's College of HMCT, Pune, Maharashtra, India
}

\section{ABSTRACT}

Tourism and in turn hospitality industry is booming in leaps and bounds. Tourism in India is predicted to be the second largest employer by 2019 providing direct employments. There are huge career opportunities available for the students in these sectors. Few years back, being a chef was looked down upon. However, today because of the social media and overall awareness, this profession has got popularity and status as well. Further, due to globalization, chefs have greater overseas career opportunities like cruise lines, Cookery shows, Health clubs, Casinos, Hotels, Specialty Restaurants, Motels, Inns, Fast Food Chains, Industrial Caterings, Flight Kitchens etc. This paper aims to study if the students in India today are keen to take up culinary profession abroad. It also tried to find out the preferred destinations by the students for the culinary profession. The professional attributes which the employers look for, while recruiting and the skills perceived by the students as essential are evaluated during the research. The gap between the curriculum and industry expectation is studied as well. The research shows that the industry perceives soft skills and attitude as important attributes as skills can be taught and honed. The students however perceive knowledge and culinary skills as required attributes. This paper aims to provide guidelines to the students looking forward to take up culinary profession abroad about the attributes /qualities they should possess.

\section{INTRODUCTION}

Globalisation has helped to boost the tourism industry worldwide, in turn the hospitality industry as well. Being an inseparable part of tourism industry it also has flourished incredibly in terms of products and services to be offered to the customers. The social media and television has increased awareness, popularity and status about the culinary profession. People have become curious and attracted towards the profession as one of the wiser option for a career. As a result, number of aspiring chefs have opted the formal education to become culinary professional in considerable numbers. This requirement is been fulfilled by many educational institutes in the country by imparting formal education to the upcoming chefs.

This study focuses on the education provided by the institutes and the skills required by the industry. It is been observed that there is a huge difference between the demand and supply in terms of professional attributes to be possessed or delivered by the entry level chefs. The qualities which are perceived essential by the students are different from those required by the industry professionals. Industry pays more attention towards the attitude and soft skills of the new joinees. According to the industry experts, if the fresher possesses the basic knowledge and right attitude the required skills can be honed as per the requirement to turn him into a better culinary professional.

The employee turnover is very high in Indian hospitality industry due to stretched working hours, shortage of skilled staff, lack of acknowledgement by the society with few exceptions like celebrity chefs, and negligible salaries in proportion with the average living standards in India are some of the key reasons for the students of Indian hospitality industry to switch to other professions.

Those students who are willing to pursue their career in culinary, prefer to go abroad as the working hours 
are defined, working conditions and salary structure are better as compare to the Indian hospitality industry. The working infra-structure such as working space, latest equipments with latest technology, the safety concern given to the one's life, medical facilities, proper implementation of lab our laws, humane treatment by the management and last but not the least the exchange value of the foreign currency are the other motivating factors to go abroad.

This study aims to make the students understand and aware about the gap between the attributes required by industry and the education they have received, and prepare themselves accordingly. This will help them to avoid the disappointment or rather the failure in the very beginning of their career abroad if they get it through the opportunity of working abroad as a culinary professional. This understanding of the existing gap will help the students to opt for the career opportunities abroad.

\section{LITERATURE REVIEW \\ 01}

Tanya Ruetzler, Jim Taylor, Dennis Reynolds, William Baker(2010) has studied in their paper "Understanding perceptions of professional attributes using conjoint analysis" that institutes prepare students to meet industry expectations. They have explored the insight about the professionalism which includes the attributes and are considered as indicators of future job performance. Further how these attributes differ among hospitality students, faculty, and industry representatives was studied. The study indicates that employers emphasize more on interpersonal skills, interview preparation, ability to work with others, and alignment with the organizational culture when deciding whom to hire.

\section{2}

Wen-HwaKo(2012) tried to relate and evaluate the actual learning by the hospitality students and their performances in an effective manner which would develop professional competence. It was observed that there is notable connection between the changing factors of learning, learning performance and the professional competence of the hospitality college students. This was compiled by studying the job satisfaction, course satisfaction, practice scores and semester GPA. It also stated that there is no respective comparison between the certifications acquired and the actual culinary management skills that one possesses. It has also been realised that the professional competence is bridging element between the effective learning and learning performance of the hospitality college students.

\section{3}

Wen-HwaKo(2010) objective was to overview the professional competence of the hospitality students in culinary skills. A questionnaire based on the five factors which describes the capability of a hospitality student such as basic culinary knowledge, culinary innovation, culinary basic skills, culinary management, and culinary attitude was drafted and given to the students for self-assessment and the response was analysed. The analysis highlighted that the factor 'culinary attitude' marked the preferred competency factor whereas 'culinary innovation' was at the last position. Working and senior members had significantly higher scores in culinary management. Students who were culinary certified had significantly higher scores in culinary basic knowledge and culinary attitude. Further the analysis showed that culinary attitude was a required positive competence and comparatively other competency factors were not so preferred for the career choice of a chef.

\section{4}

To understand the definition of cooks and chefs from the culinary industry, the researcher Mack Glenn R. Nova from South-eastern University (2012), has evolved this mixed methods dissertation which also have provided an opportunity for him to know the professionalization process of the culinary industry in detail. The culinary educationalists carry different concepts and values of professionalism even though they do teach or communicate the common standards and principles of behaviour for attaining the professionalism. The author has observed views of employees of professional hospitality organisations to collect the data regarding their understanding about the requirement of professional qualities to become a cook or chef. The author wanted to know that which factor of the professional attributes require more attention in concern with its improvisation and have recommended specific training programmes in the workplace and in the culinary classrooms to overcome the current inadequacies of professional values, attitudes, or behaviours.

\section{5}

This study of "Recipes for success: culinary styles, professional careers, and institutional patterns in the field of high cuisine" is conducted in the restaurants 
serving the high cuisine or the haute cuisine of New York City and San Francisco to investigate the social logic of creation by the authors Leschziner and Vanina(2007). The data has been collected by interviewing and observing in - depth life and the systematic culture of the forty five elite chefs in their restaurant kitchens. The author has examined the chef's culinary styles, status, their professional strengths which are their moving forces as well, creational processes, and relations with others in their field which explains their determined choice of the dishes and their career, their relations with colleagues, chef's understandings of their contribution to the work and social relations as well. He has studied in detail the specific highlights of the activities which are related to that particular cuisine to explain the patterning of culinary creation, and demonstrate that such patterning is associated to status.

\section{6}

In this study the authors Hsiu-Hsun Lin and YuhJyeCherng(2006) have approached the topic as per the understandings and expectations of the industry professionals from the graduates or the educated students from culinary schools at entry levels in the industry. The topic "Determine the Demand of Professional Development for Culinary Arts Faculties: Aligning Industry Needs and Educational Preparation" also focused through a survey upon the culinary college teaching staffs development considering the actual and latest requirement of the hospitality industry. The survey evaluated the outcome of colleges by relating the teacher's preparedness with the actual needs of the industry. The strength and weaknesses of the students in concern with their initial performance in the industry will highlight the quality of education they have received in their learning phase. The author also have suggested that there is a need to draft or construct training programmes which will provide further improvements in teachers to meet the actual practical requirement of the hospitality industry from the fresh culinary professionals passing out of the culinary institutions. The training programmes or activities should consist of Industrial Training after certain period of time which will make them able to maintain themselves updated with the current requirement of culinary skills and knowledge. Which they can impart to their pupils and benefit the school, the students and finally the hospitality industry.
07

The researcher Huang and Yijun M.S. of Purdue University (2014), has opted to understand and realise the difference between the hospitality recruiters and the hospitality students about what knowledge, skills and abilities are required by the hospitality graduates to secure an entry level managers employment in the industry. The literature he has referred previously for the research "Gap between Hospitality Employers' Demands and Hospitality Students' Perceptions Regarding Entry-Level Managers' Requirements in the United States." In which they have used diverse methods to collect the related information which states that students and recruiters do have different opinions, especially for those basic or person-related features. The writer has taken help from the statements of other researchers to understand whether students' thinking matched the industry's thinking. The results showed that recruiters generally ranked these statements higher than students did, especially when it came to ethical issues. Students tend to rank relocation and relevant working experience more highly than recruiters do.

To bridge the gap, industrial internships of students might provide as a help as long as they are continuously followed. Case studies, Previews with site visits and guest lecturers work as a bonding with the industry. Teachers and instructors of the educating institutions should observe the syllabus closely which needs to be in concern with the global trends so that students have a broader viewpoint.

\section{8}

Author Colin Philip Roche (2012) of Florida Atlantic University with the emphasis on examining the perceived value of formal culinary education on industry career success from the perspective of those who carry the maximum amount of the hiring of the culinary professionals. This Title "Canadian Professional Chefs' Perceived Value of Formal Culinary Education and its Relationship with Industry Success" is especially in concern with the Canadian professional chef's and the Canadian hospitality industry. The survey which was carried out, showed that Canadian professional chef's do believe the value and benefit having the formal culinary education, which would help in optimising the opportunities of stepping up in the career as well as the financial remunerations. Simultaneously the survey also focused on the fact that till date very limited research has been carried out to identify the need of formal 
culinary education which is based on the actual requirement of the hiring organisations from the industry. The present industry trends are insisting on having formal culinary education which is equivalent to the diploma or certificate in culinary arts. The Canadian chef's not only value the formal culinary education but also preferring the organisation who understands and maintains the same. This survey gives a clear understanding that Canadian professional chefs need and want an educated workforce and believe the value and benefits one receives from their formal culinary education which is worth the costs of obtaining that education. Universities, colleges and institutions who are graduating hundreds of students yearly with some form of culinary education will use this as a guiding directive as they are feeling the pressure from the concern authorities to prove the value of education they are providing compare to the tuition fees and associated costs involved

\section{9}

The researcher Williams, Richard L. (2008)have studied two different formats of culinary programs in a said university with the purpose to identify the effectiveness and positive impact on the students who are pursuing it. There were two formats which were under the observation, a Traditional program and an accelerated program provided in Two years associate degree curriculum. The accelerated program had more clock hours spent in the kitchen laboratory and the traditional program had more classroom hours. Which provided the data showing that the accelerated program students are performing better than the classroom students in a laboratory-based practical test which is also a requirement to complete the program. This indicates that teaching methods of accelerated program has better impact on students. Also the classroom program students were showing the knowledge they have gained through the demonstrations from the instructors is also had an upper hand in comparison with the accelerated program students. So these findings from this study may reveal a specific program format that will provide the students with best learning opportunities in the classroom and in the kitchen laboratory as well.

\section{0}

Study of "Evaluating Food and Beverage Courses in Higher Private Tourism and Hotels Institutes in Alexandria: Professionals' Perception by Youssef Agwa, Wael Aziz and GamalKhalifa (2018), which was carried out in Alexandria, Egypt to evaluate the importance of Food and beverage courses for the fulfilment of hospitality industry in regards to professional man powers availability in the country. The study is based on the data collected after interviewing the professionals with a structured interview. The findings which came across there is a difference between the professionals understandings regarding requirement of an academic qualification and level of professionalism by a candidate venturing into the hospitality industry. So the observation which is mentioned says that some of them have the required skills and professionalism which are enough and meet the requirements, other believed that there is more need for teaching staff to be trained and developed.

\section{1}

The authors KushaPandit Chawla and Kuldeep Kumar (2017) have tried to identify the skills required by the hospitality industry. The qualities which the students found ideal and what they possess after completion of the course are compared for the study. The study has tried to make the faculty focus on making students employable and develop managerial skills in them. Development of practical skills and exposure so as to inculcate professional attitude is stressed upon. The authors also believe that the expertise of the professional is the outcome of educational learning and guidance.

\section{2}

YukselS. (2013) in his paper "Recruiter's Expectations vs. Student's Perceptions, Descriptive Approach to Hospitality Skills in Oman" has analysed that for the students mostly operational and knowledge skills are the most important hospitality skills whereas for recruiters soft skills and conceptual skills of applicants are more important.

\section{3}

The author Po-Fen Chen (1995)have studied the curriculum relevancy and attitudinal learning outcomes in preparing hospitality management students to meet industry needs. Appearance and attitude were amongst the important attributes required as per the students. However there is a vast difference in the attributes what hoteliers are looking for at the entry level and the qualities actually possessed by the students. The hoteliers have suggested few recommendations to bridge the gap between the industry expectations and the existing set of attributes of the hospitality students. 
III. OBJECTIVES OF THE STUDY

1. To analyse if the current syllabus complies with the need of the students.

2. To find out the willingness of students to opt for career in culinary in abroad countries.

3. To study the students awareness about the professional attributes required for culinary career abroad

4. To provide the students with the guidelines required for the same.

5. To find out the preferred destination by the students for the culinary career.

\section{LIMITATIONS OF THE STUDY}

1. This study is purely based on the information given by the students of Bachelor of Science in Hospitality Studies and Bachelor of Hotel Management and Catering Technology of All India Shri Shivaji Memorial Society's College of Hotel Management and Catering Technology

2. The study is conducted in the current scenario and the opinions, perception and expectations of the respondents may differ with time.

3. The study does not differentiate respondents on basis of their demographic factors which may have an influence of their perception thereby identifying scope for further research.

\section{RESEARCH METHODOLOGY}

The data required for the research was collected using the following technique:

\section{Survey with Structured Questionnaire:}

The researcher conducted a survey through a well drafted questionnaire covering all the points related to the Research topic. This was then floated online to collect the responses from the desired segment of students which is the Final Years student of both the programs respectively Bachelor of Science in Hospitality Studies and Bachelor of Hotel Management and Catering Technology of All India Shri Shivaji Memorial Society's College of Hotel Management and Catering Technology

\section{$>$ Internet:}

The general information is compiled to illustrate the subject in detail with some additional data.

\section{DISCUSSIONS, CONCLUSIONS \\ FINDINGS \\ \& \\ DISCUSSIONS}

The Certain qualities or attributes needs to be acquired by a student simultaneously while pursuing the formal culinary education to succeed in this industry as a top chef must be:

1. Business-Minded: A successful chef should know that the quick preparation, quality of food and outstanding presentation are the key factors to get the repeat business. This can give the revenue to the organization as well as the popularity and status to the chef.

2. Committed to Quality: A chef should always stick to the quality of the food he is going to produce. He should follow the rule or rather the principle that "Only Quality will produce Quality". The quality of food would create trust in the customers which would beneficial for everyone working in the culinary department.

3. Creative: creativity is such an attribute which will keep the chef all the time updated with the market and cooking techniques as well as presentation styles. It gives an advantage to the chef to stay in the front in the culinary fraternity.

4. Dedicated: Careful study and practice of food production techniques would reflect in updation for being a successful chef. This should be continual process throughout.

5. Eye for Detail: detailing of all the process involved in the food preparations is always essential to take care of the sanitation, freshness and the preparation - to ensure a perfect meal every time. This ultimately benefits the people being served in the restaurant by getting the maximum worth of their money.

6. Adept: There are several meals to be cooked at once and there are different processes involved in it, so a chef needs to be very competitive in managing the time of preparations without compromising the quality of the food cooked. Synchronizing/aligning all the elements in timely manner is a great skill indeed.

7. Team Spirit: Since a Kitchen job cannot be performed individually rather any operational work cannot be completed alone, considering this as an essential part of the food production team one must work well with any team member to deliver his contribution at its best at all the time, which will make sure that every patron has a great meal experience.

8. Passionate: A chef needs to be very attached to his work and should perform it with intrinsic love towards the culinary art. 


\section{Traits required for culinary professionals:}

\section{ESTEEM FOR KITCHEN BRIGADE}

In the heat of kitchen operations which is equal to a battle, all cooks must respect the chain of command with considering the respect of each and every member of the Kitchen Brigade. As everyone has distinctive set of responsibilities, the feeling and understanding of "Everything is Everyone's job" is mostly important. What so ever is the situation and whoever is the person you need to work as per the requirements of a successful kitchen operation.

\section{ADMIRATION FOR COLLEAGUES}

Kitchens must always remain the example of respect for a diverse workforce-realize that everyone's success depends on the success of everyone else. One must respect the colleagues for their contribution towards the job allocated.

\section{RESPECT FOR INGREDIENTS}

As cooks, we are privileged to work with exceptional fresh ingredients that farmers, ranchers, cheese makers, charcutiers and butchers, vintners, fisherman and distributors worked painstakingly to bring to our back door. We must respect each and every one of them as well as the animals and plants that gave their existence for a great meal.

\section{RESPECT FOR SPACE AND EQUIPMENT}

A chef should be respecting the work space he is going to work in, as well as the small tools and kitchen equipments irrespective of their sizes. As it takes a lot of cost to install them, if a good care is been taken they function properly and contribute majorly to the efforts of a successful chef.

\section{RESPECT FOR THE CUSTOMER}

The father of the nation Mahatma Gandhiji's famous quote "Customer is God and He is always right" is perfectly applicable to all the businesses. As the customer purchases your products or services by paying the price of it which you decide as a seller or provider. It's the responsibility of the chefs to make sure to deliver the best of the best quality product or service.

\section{RESPECT FOR THE UNIFORM}

Each profession in today's time has defined uniforms with all the minute details eg the fabric, the style, colour etc. This is evolved over the period on the basis of the safety and performance of the professional person. That is why it is said that it represents the history of that profession so one should wear it with pride which is going to keep him safe and highly contributing member. A chef's uniform represents the work, dedication and pride as well.

\section{ADHERENCE TO THE BASICS:}

It is a dream of every chef to get appreciation and recognition for his creations and his style of cooking. However he can reach to the goal only if he follows the basic methods of cooking and the established procedures of the art of culinary. Chefs should always stick to the basics which will make them establish their own cooking style and their signature creations when time comes.

\section{PRIDE FOR FOOD BUSINESS:}

A successful culinary professional always respects his food business, as in any country it is one of the largest sectors where employment ratio is always high based on the skills. As an individual of culinaire profession chefs must respect and feel pride about it and contribute with all the strength, dedication and love.

\section{FINDINGS}

Following are the observations recorded after a survey of 107 student's mindset through a neatly structured questionnaire. The replies received are explaining at present thought process as well as awareness of this generation of students. The students are very well concerned with this topic and consciously thinking about their career.

The questions asked and the responses received maximum percentages are mentioned below for the reference -

(Q.1) kindly express your views regarding the existing curriculum

1. Enough emphasis is given on developing culinary skills. (45\%)

2. Sufficient practice is provided for actual operational procedures as per the industry. (46\%)

3. Availability of quality ingredients in sufficient quantity. (49\%)

4. Limitations on skills and knowledge of the faculty members to deliver the requirements of the students in concern with career in abroad. (34\%)

5. Does the present syllabus and teaching techniques prepare the students to make themselves ready to choose this option of career in abroad? (52\%) 


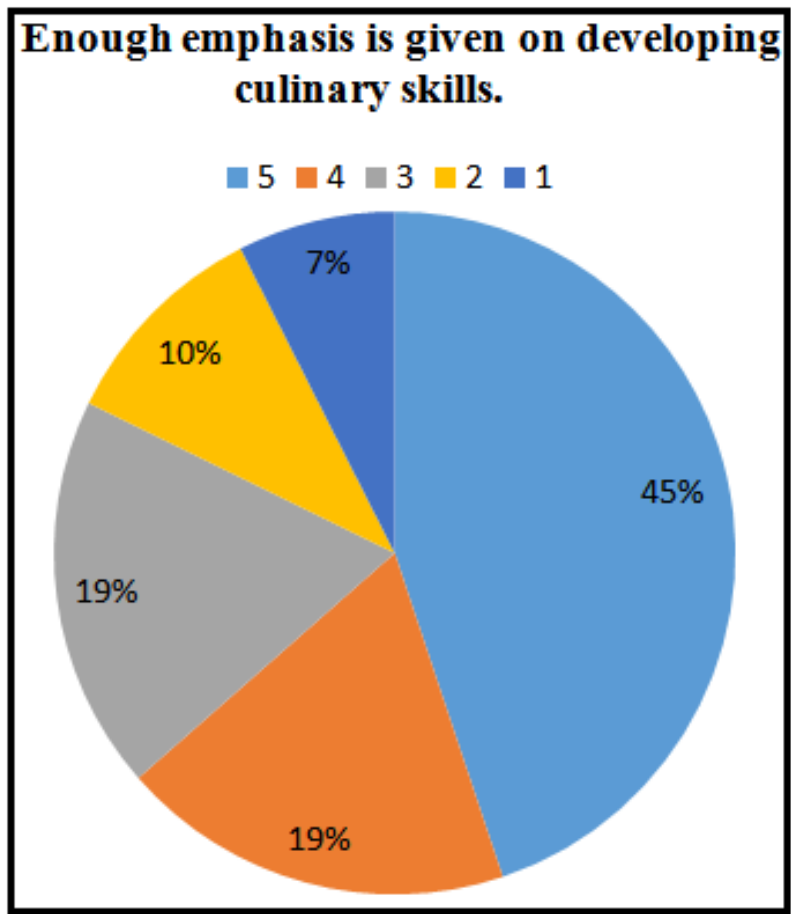

Sufficient practice is provided for actual operational procedures as per the industry

$$
\square 5 \square 4 \square 3=2 \square 1
$$

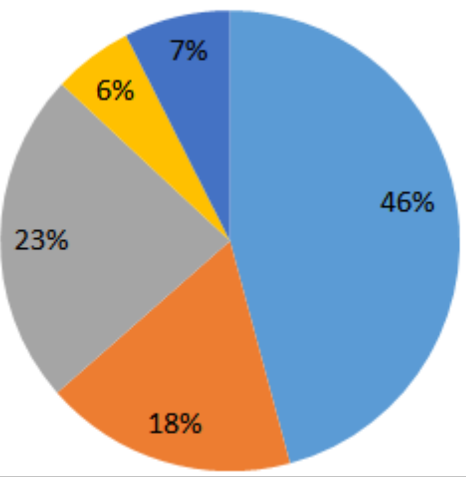

Availability of quality ingredients in sufficient quantity

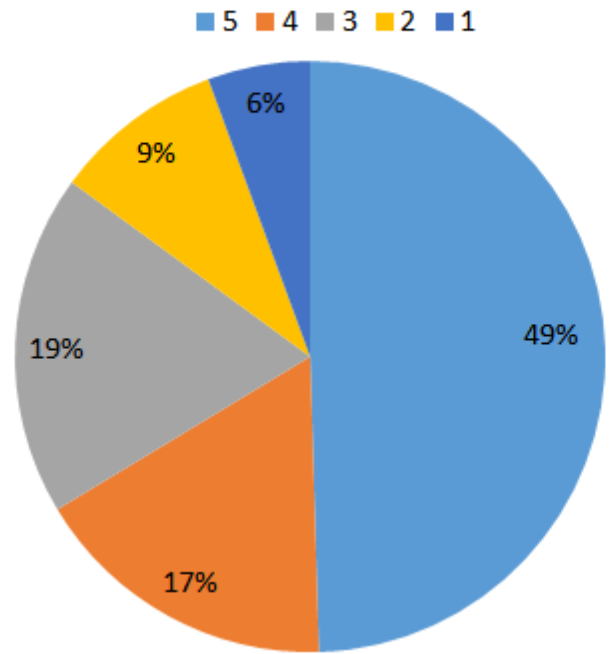

Limitations on skills and knowledge of the faculty members to deliver the requirements of the students in concern with career in abroad

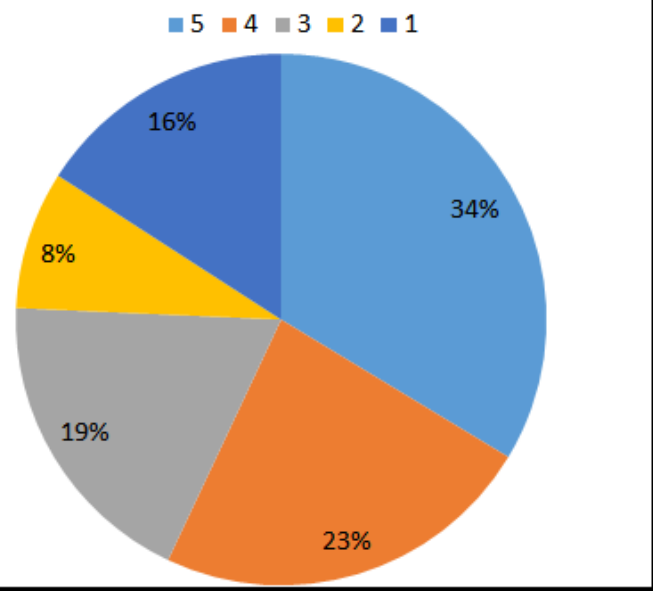

Does the present syllabus and teaching techniques prepares the students to make themselves ready to choose this option of career in abroad?

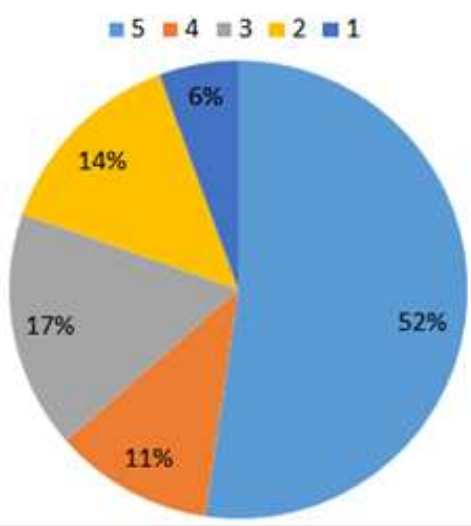

(Q.2) would you like to opt for a career in culinary abroad after completing the graduation?

Yes $-(73 \%)$

No - $(2 \%)$

Can't say - (25\%)

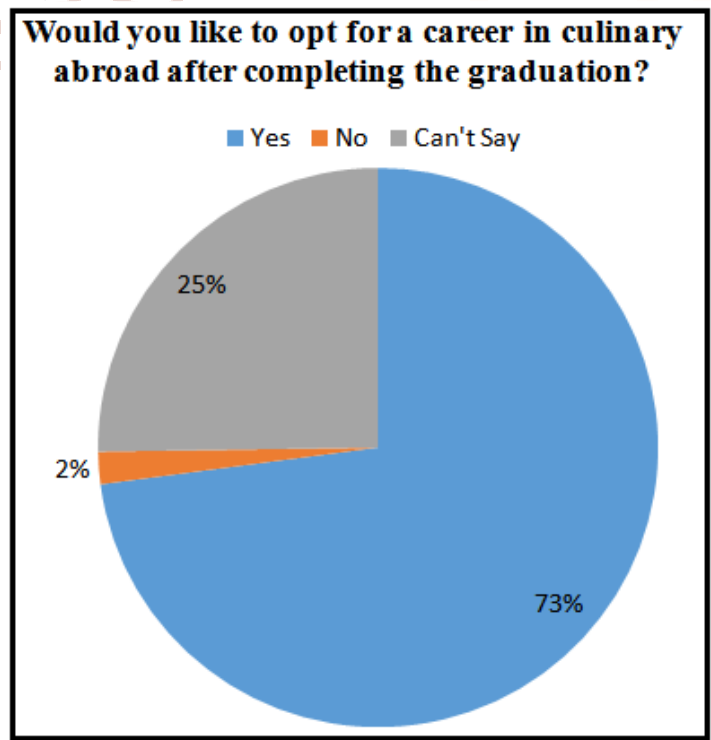


International Journal of Trend in Scientific Research and Development (IJTSRD) ISSN: 2456-6470

(Q.3) which country would you prefer to go?

a. South East Asia - $(0 \%)$

b. Europe - $(31 \%)$

c. USA - $(27 \%)$

d. Australia - (11\%)

e. New Zealand - $(4 \%)$

f. Canada - (15\%)

g. Rest of the Asia - (12\%)

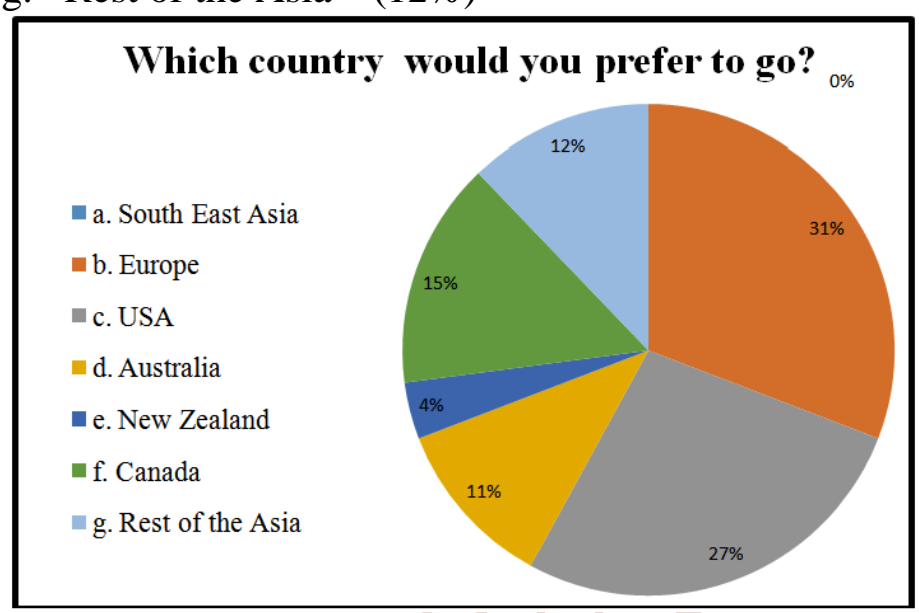

(Q.4) Rate the qualities you think are required to shape up a career abroad

1. Inquisitive Nature - (44\%)

2. Striving for Knowledge - $(55 \%)$

3. Ability and preparedness to work long hours$(62 \%)$

4. Well-read and well referred of basic culinary books- $(51 \%)$

5. Clear understanding about basic kitchen concepts$(68 \%)$

6.

\section{Inquisitive Nature}

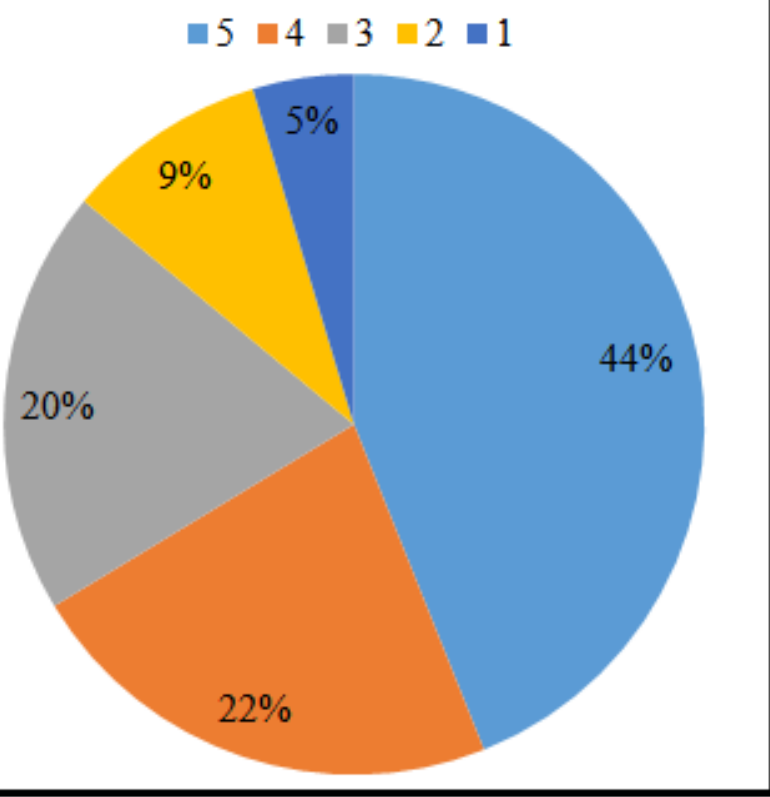

\section{Striving for Knowledge}

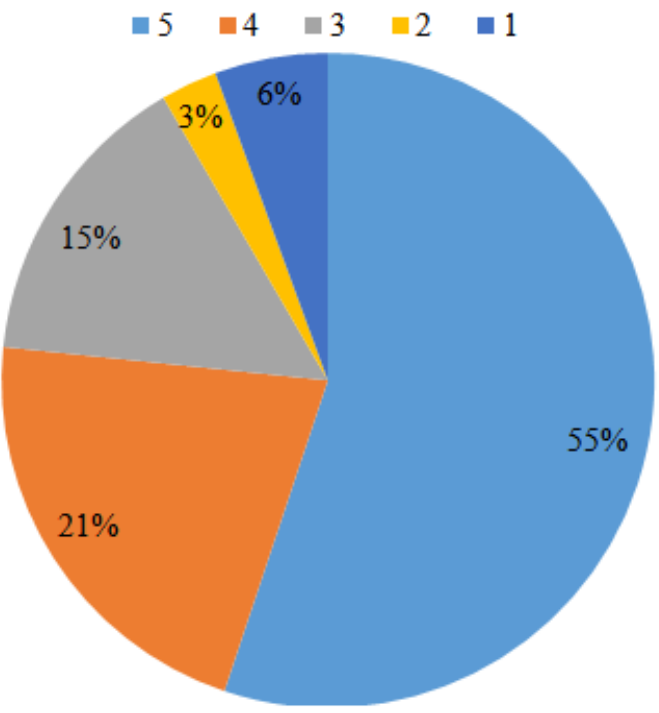

Ability and preparedness to work long hours

$\square 5 \square 4=3 \backsim 2 \square 1$

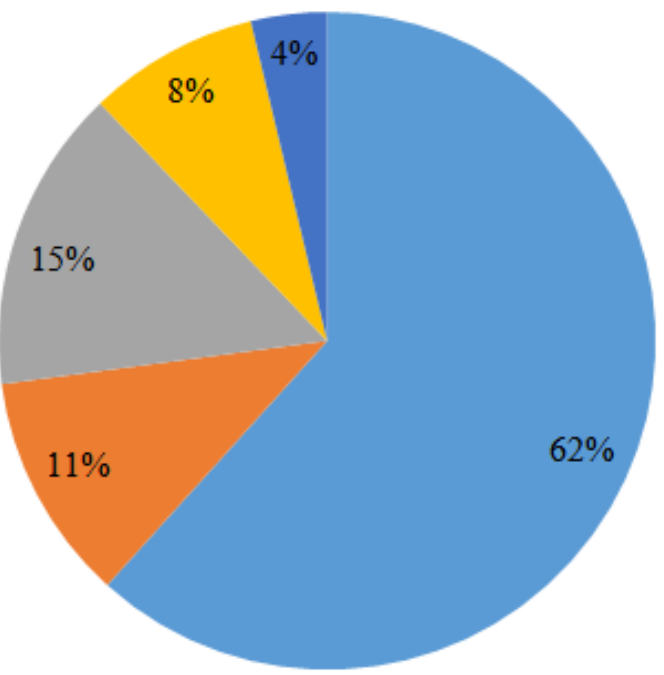

Well-read and well referred of basic culinary books

$$
\because 5=4 \backsim 3=2 \backsim 1
$$

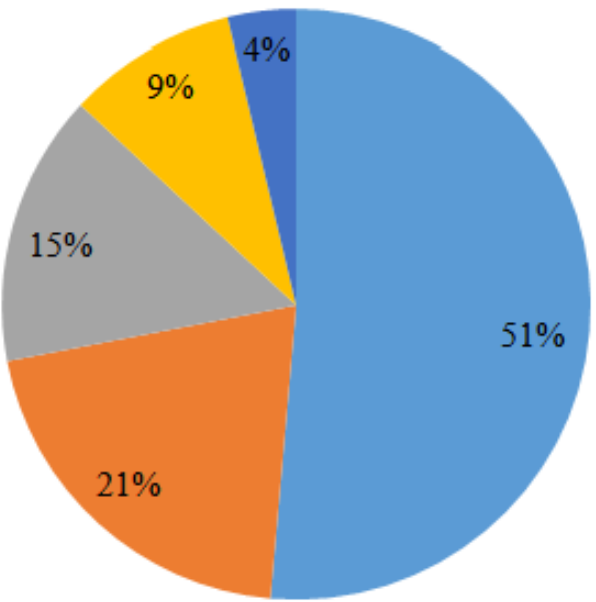




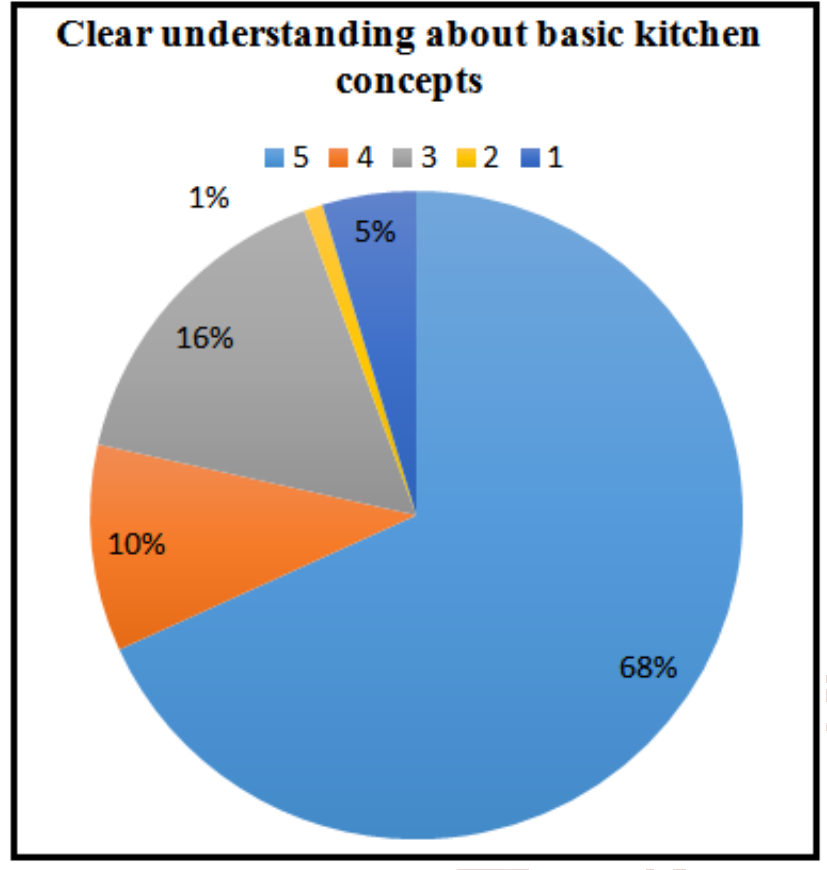

\section{CONCLUSIONS}

The findings of the research can be concluded as under:

$>$ The existing curriculum/syllabus of culinary education needs a revision to inculcate the required theory and laboratory based practicals.

More and more students from the country's hospitality institutions would like to choose the option of developing their careers in abroad due to the mentioned shortfalls here in Indian hospitality industry.

An obvious selection of countries on the basis of infrastructure and growth opportunities was seen in the responses. The preferred ones are Europe, USA and Canada

The qualities which are very much necessary to carve/shape career in abroad were responded considering the very basic requirements on priority basis namely: Clear understanding about basic kitchen concepts, Ability and preparedness to work long hours, Striving for Knowledge, Well-read and well referred of basic culinary books and Inquisitive Nature respectively.

\section{SUGGESTIONS}

On the basis of the responses from the students on "Professional Attributes required by Culinary Students for Career abroad" the following suggestion could be made:

$>$ The syllabus/curriculum of the culinary programs could be improved further to accommodate the required/essential factors to develop the expected professional attributes. The enhanced programs would create maximum opportunities for students to choose their culinary career on the home turf as well as in the other countries.

Awareness programs about the attributes related to the personality development can be included as a workshops

\section{BIBLIOGRAPHY \& REFERENCES}

1. Understanding Perceptions of Professional Attributes Using Conjoint Analysis Author Links Open Overlay Paneltanyaruetzler, jimtaylor, dennisreynolds, williambaker (2010) https://Doi.Org/10.1016/J.Ijhm.2010.09.006

2. A Study of the Relationships among Effective Learning, Professional Competence, and Learning Performance in Culinary Field

(2012) Author: Panelwen-Hwako https://Doi.Org/10.1016/J.Jhlste.2012.02.010gets Rights and Content

3. To Evaluate The Professional Culinary Competence Of Hospitality Students WenHwako (2010) https://Doi.Org/10.1080/15428052.2010.511101

4. Professionalism In Culinary Arts: Perceptions And Assessments For Training And Curricular Design(2012)

Mack, Glenn R. Nova South-Eastern University, Pro-Quest Dissertations Publishing, 20123535705

5. Recipes For Success: Culinary Styles, Professional Careers, And Institutional Patterns In The Field Of High Cuisine (2007)

Leschziner, Vanina (Author) Rutgers University; Graduate School - New Brunswick

6. Determine The Demand Of Professional Development For Culinary Arts Faculties: Aligning Industry Needs And Educational Preparation

Hsiu-Hsun Lin and Yuh-Jyecherng (2006)

7. Gap between Hospitality Employers' Demands and Hospitality Students' Perceptions Regarding Entry-Level Managers' Requirements in the United States.

Huang, Yijun, M.S., Purdue University, (2014)

8. Colin Philip Roche (2012), Florida Atlantic University

Title: Canadian Professional Chefs' Perceived Value of Formal Culinary Education and Its Relationship with Industry Success Institution: 
International Journal of Trend in Scientific Research and Development (IJTSRD) ISSN: 2456-6470

Dissertation Advisor: Dr. Deborah L. Floyd Degree: Doctor of Philosophy Year: 2012

9. Williams, Richard L. (2008)

The Impact Of Accelerated Versus Traditional Learning with A Practical Test in Advanced Culinary Skills at Fox Valley Technical College American Psychological Association, 5th Edition

10. Evaluating Food And Beverage Courses In Higher Private Tourism And Hotels Institutes In Alexandria: Professionals' Perception Youssef Agwa, Wael Aziz, Gamalkhalifa(2018)

11. Identifying Competencies And Students Career Opportunities In Hospitality Industry -
Kushapandit Chawla, Kuldeep Kumar(2017), Assistant Professors, A. P. Goyal Shimla University

12. Recruiter's Expectations Vs. Student's Perceptions, Descriptive Approach to Hospitality Skills in Oman-Mr. Sedatyuksel(2013) Senior Faculty, College of Applied Sciences, Department Of International Business Administration, Sohar, Sultanate of Oman.

13. General Managers And Four-Year Students Evaluate Attributes, Qualities, Competencies And Skills For Hotel Management Entry-Level Positions: A Case Study By Po-Fen Chen(1995)

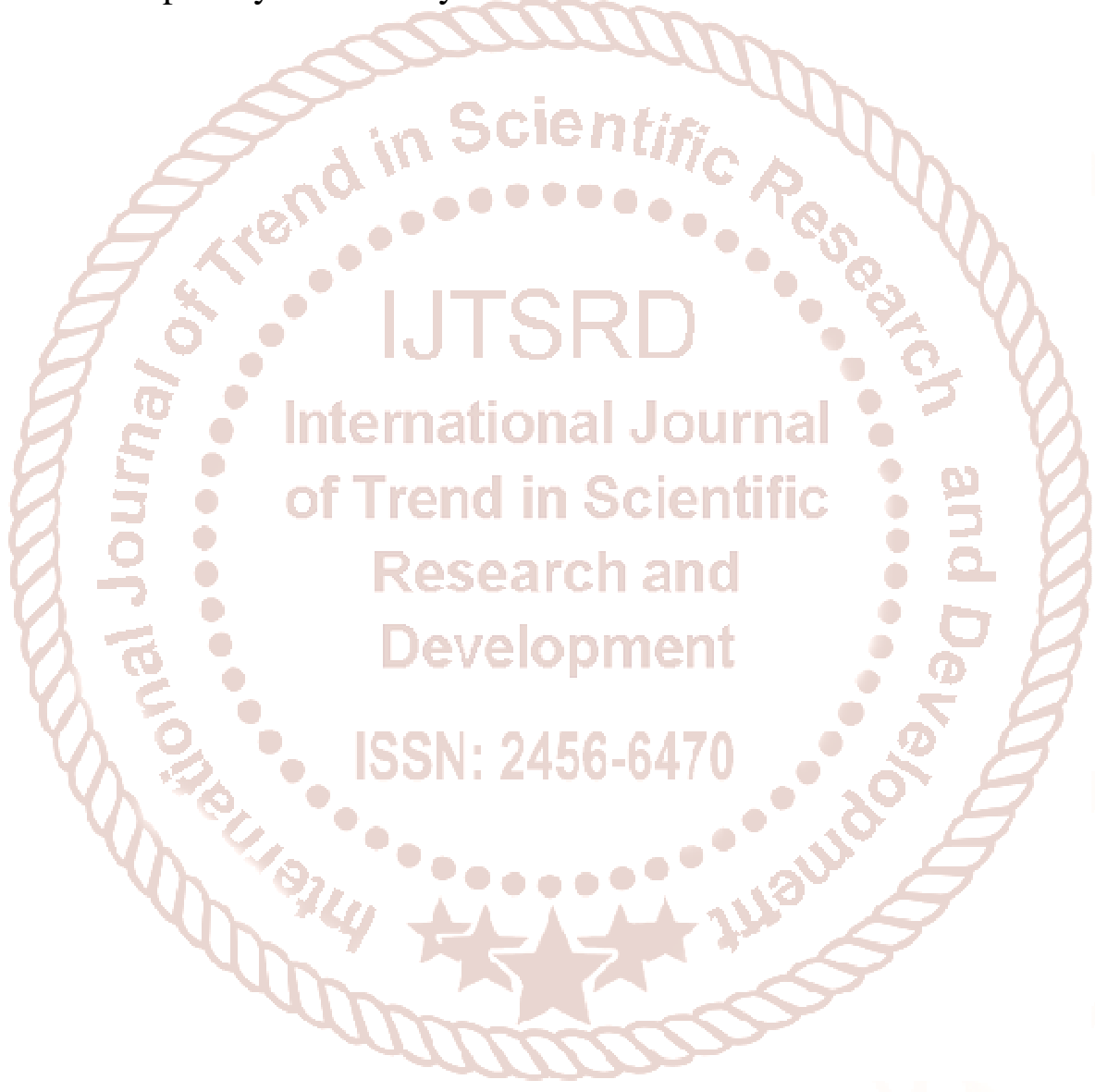

